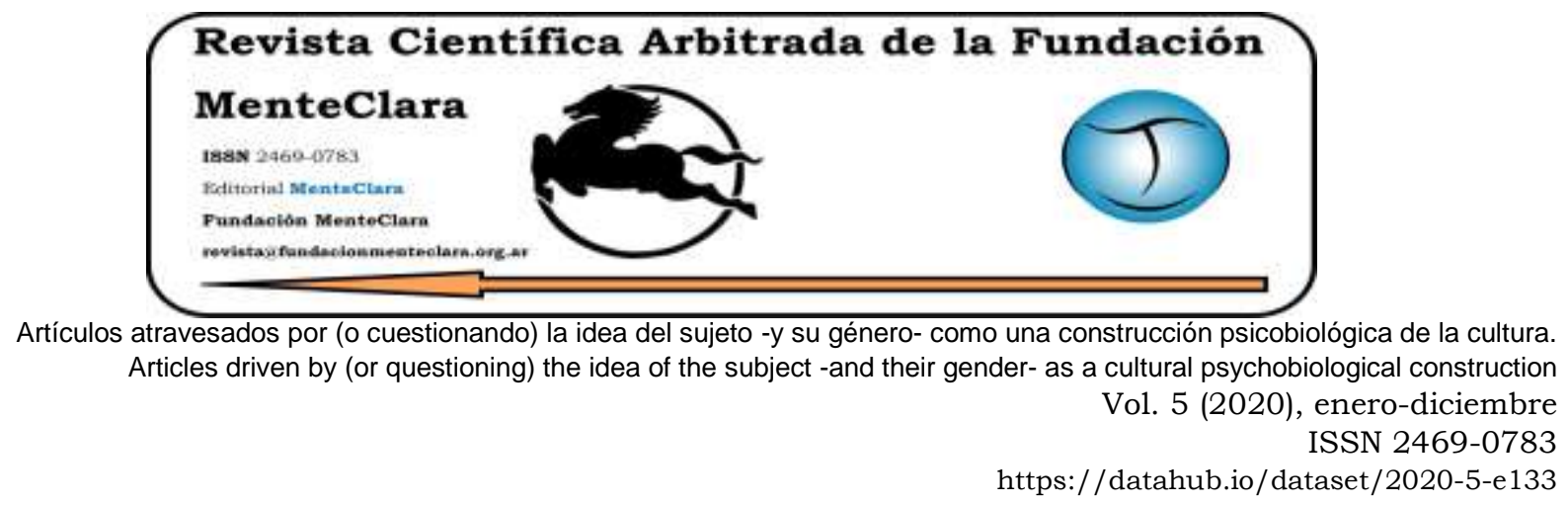

\title{
THE USE OF TRANSITIONAL SPACE IN PSYCHOTHERAPY WITH THE EXISTENTIAL CONCERNS OF BORDERLINE EXPERIENCE
}

\author{
EL USO DEL ESPACIO TRANSICIONAL EN PSICOTERAPIA CON LAS \\ PREOCUPACIONES EXISTENCIALES DE LA EXPERIENCIA BORDERLINE
}

Rudolph Bauer rbauer@rsbauer.net

Center for Consciousness Studies and Washington Center for Phenomenological and Existential Psychotherapy Studies. United States of America

Cómo citar este artículo / Citation: Bauer R. (2020). "The use of transitional space in psychotherapy with the existential concerns of borderline experience". Revista Cientifica Arbitrada de la Fundación MenteClara, Vol. 5 (133).

DOI: https://doi.org/10.32351/rca.v5.133

Copyright: (C) 2020 RCAFMC. Este artículo de acceso abierto es distribuido bajo los términos de la licencia Creative Commons Attribution 4.0 International License (CC BY 4.0). Recibido: 18/12/2019. Aceptado: 11/01/2020 Publicación online: 12/01/2020

Conflicto de intereses: None to declare.

\begin{abstract}
This paper describes experiencing the state of transitional awareness that facilitates the ongoing psychotherapy process within borderline states of concern. The paper focuses on the utilization of the transitional states of awareness so that a person's existential experience of the borderline situation can be transformed. The particular ego-self deficits of the borderline situation are elaborated from an existential self object relations viewpoint. The borderline concern is profoundly existential and ontological. The transitional space of awareness is the doorway into our embodiment of the field of Being which is the field of Self.
\end{abstract}

\section{Resumen}

Este documento describe la experiencia del estado de conciencia de transición que facilita el proceso continuo de psicoterapia dentro de los estados límites. El documento se centra en la utilización de los estados de transición de conciencia para 
que la experiencia existencial de una persona en situación límite se pueda transformar. Los déficits particulares de ego-yo de la situación límite se elaboran desde un punto de vista existencial de relaciones de auto-objeto. La preocupación limite es profundamente existencial y ontológica. El espacio de transición de la conciencia es la puerta de entrada a nuestra encarnación del campo del Ser, que es el campo del Ser.

Keywords: tantra; experience; limit; transitional space; anguish; existential; selfliberation; borderline; psychotherapy

Palabras Claves: tantra; experiencia; limite; espacio transicional; angustia; existencial; auto-liberación; borderline; psicoterápia 


\section{Introduction}

This paper articulates the use of the Transitional Space of Awareness in the psychotherapy of persons who are experiencing the existential situation that is often described as the borderline situation and borderline experience. I do not speak about the borderline patient but the borderline experience or situation as this experience is foundational within human existence. Psychoanalytic investigations based on the work of object relation theorists such as Guntrip (1969), Winnicott (1965), Mahler (1971), and Kernberg (1967) suggest that this borderline experience reflects a developmental fixation in ego development which initially occurs during the early childhood stage of separation/individuation. A number of factors: genetic, environmental, and traumatic interpersonal may interfere with the child's progression from a symbiotic relationship with their mother to a position of relative separateness. This difficulty is suggested to occur following self-object differentiation, but prior to the development of object constancy and corresponding self-constancy.

Structural impairment during this period results in the pathological continuance of splitting as a defense, both in terms of self and object; "I am either all good or all bad--you are either all good or all bad". This continuous use of being split results in limited reality testing, limited ability to tolerate anxiety, frustrations and limited ability to sustain a stable and integrated sense of ongoing continuity of self. This continuity of self is the sense of ongoing continuity of Being-ness.

The structural framing I have described here may be experientially accurate but none the less may over emphasize the developmental frame and under emphasize the role of acute and cumulative trauma in the creating of this terrible experience of annihilation anxiety and of falling into being-less life and empty existence. The borderline experience and 
situation is the horrible experience of Existing without the sense of our embodied Being which is our sense of vital embodied self. Our sense of Being and our sense of self are intimately intertwined. We human beings are onto-ontological beings.

Phenomenologically and experientially, there is an existential terror that is expressed in the dialectic and polarity of the relational fear of being abandoned and/or the of being completely absorbed by another. The person's inner experience of sense of self is at times empty and vacuous. And at times there arises within the person a driven-ness of compulsive behaviors which are desperate attempts to avoid the experience of unbearable ontological annihilation anxiety and the experiential sense of being-less selfless non -embodiment. Living within a dissociative state of being is living within a sense of being-less-ness. Non embodiment implies a fragmented and disintegrating sense of embodied self and embodied being-less-ness.

\section{Phenomenological Experiencing}

This form of phenomenological experiencing reflects the drama which is so pervasive through many forms of clinical diagnosis and is profoundly existential and truly a part of our existential human experience. So in this paper, I am not discussing a psycho-diagnostic category but rather this human existential dilemma that may arise in time for everyone and anyone. This fragmenting event may arise for some people as they enter into a new developmental life phase. You can think of Erik Erikson's life cycle, and the bewilderment that may arise as a person makes the transition from one phase of life into another existential developmental phase -with new and challenging developmental tasks(Erickson, 1975). The experiencing of transitional of awareness and being 
in the transitional state of relatedness facilitates the ongoing existential psychotherapy process of healing the lack of ongoing continuity of Being, as well lack of ongoing continuity of self. By entering into the unfolding process of becoming aware of awareness there is a direct entering into the transitional state of spacious awareness. By being in transitional awareness we can directly know and experience Being. By living within this field of transitional awareness we can directly experience the field of our own embodied Being and the field of Being of others. Not only do we know and directly experience Being by living within the field of awareness, but by living within the field of awareness, we experience the embodiment of Being. Sometimes people confuse the simplistic focusing of attention as being in the field of primordial awareness. The drama of focusing our attention is a function of mind or an ego function. This is a psychological or mind form of awareness. Transitional awareness is an awareness that reflects our Being and the knowingness of Being. Our mind knows form and our awareness knows Being. The knowing of our Being is the knowing of awareness.

\section{Ontological Anxiety And Disintegration of Sense of Self}

The transitional state of awareness can provide direct support in the transforming of a person's experience of the ontological anxiety and disintegration of sense of self into an ongoing continuous sense of primordial embodied base of Being, and sense of continuous stability of ongoing continuity of sense of inner self.

The intrinsic field of our inner most awareness becomes our existential base of self and no longer is the base of our sense of self which is our fragmented and fragmenting mind. The mind does not know Being. Our mind is not our self and neither is our mind the base of our self. Our 
mind does not know the presence of Being. The feeling of our ongoing continuity of Being and ongoing continuity of self can be ruptured by our internalized states of traumatic negation.

In both borderline and schizoid states of experience, our sense of person is often located in our mind alone and we have become dissociated and split off from our basic state of embodied awareness and our embodied sense of Being. Our most basic human dissociation is the dissociation between our mind and our embodied field of innate awareness.

\section{Direct Knowingness of Being}

Our capacity to become aware of our awareness is our opening into our becoming the embodied Being of awareness. Heidegger 's wonderfully describes the nature of our Awareness as Da Sein. Da sein is the openness of human awareness to the Being-ness of Being. This is important. Da sein is the openness of human awareness to the experiential knowing of the Being-ness of Being. In becoming aware of our awareness we enter the openness of our awareness into the experience of the field of Being-ness, and the continuity of our sense of vital embodied Being-ness. Our sense of self and our sense of Being are intertwined (Heidegger, 1966).

\section{Two Ways of Knowing: Mind knowing Form and Awareness Knowing Being}

We have two ways of knowing. We are the knowing of mind and we are the knowing of awareness. Our mind knows form and our mind knows duality and our mind knows difference. Our mind knows things and our mind knows separateness. Our awareness knows Being and our 
awareness knows the oneness of Being and our awareness knows the presence of Being. Our mind knows the form of beings and our awareness directly knows the Being of beings. Our awareness knows the presence of Being as presence of self.

Our mind often misrecognizes our mind as self and our mind considers mind as the basis of self. Our awareness knows Being and our awareness knows the Being of awareness as our self. In mind alone the sense of self is related the functions of mind. The mind itself is Beingless. In becoming of aware of our own awareness the sense of self is related to the experience of our ongoing continuity of Being. In phenomenology, Awareness is Da Sein which is our opening of our awareness to Being. Awareness is our opening to the Being of our own Being and our opening to the Being of others. Awareness is our opening to the Being of the world.

When we integrate our mind within our field of awareness then we can experience the Being of form and the forms of Being simultaneously. We can experience the Being of our own form and we can experience the Being of the forms of others. We can experience the form of the world and the Being of the world simultaneously. With the integration of our mind into our awareness field, we can experience our sense of Being of our own embodied sense of self. We can experience living in a field of Being. We can experience Being in the world as Being in the Field of Being.

\section{Becoming Aware of Awareness}

Winnicott introduced his understanding and experience of transitional space as a metaphor describing the process and personal experience of becoming aware of our own innermost awareness which has the quality of spaciousness, the quality of vital energy and the quality of the self- 
illumination and the quality of play. Transitional awareness is not an affect, nor thought, nor phantasy, nor sensation. Transitional awareness is an in-between state or place of Being. Transitional awareness is an intermediate area of experience. This knowing spaciousness provides a ontological sense of self in this sea of Being. Transitional awareness is not located within our mind. There is our mind knowing form and our awareness knowing Being. We can integrate our mind within our awareness; and experience our knowing of mind and our knowing of awareness simultaneously.

The integration of our mind and awareness allows us to know the Being of forms and the forms of Being. We can experience the various forms of affect within the oneness of our embodied self. We can experience the various forms of thought within the oneness of embodied self. We can experience the various forms of sensation within the oneness of embodied self. We can experience the various forms of imagination within the oneness of embodied self. We can also experience the non-duality of Being within the dualities of beings. And we can experience within the dualities of beings within the non- duality of Being.

Our innermost awareness is the inner openness of our direct knowingness of the field of Being. There is no one way of entering into the transitional area of experiencing. The nature of transitional awareness is open spaciousness. It is most useful to the make the distinction between mind and awareness. Awareness is the opening to the experience of foundational Being. Mind knows through thinking, through feeling, thorough sensation, through memory, and through imagination. Our mind does not know or experience Being directly. Our mind can think about Being but our mind alone does not experience Being. 
One way which is a way of entering the phenomenology of awareness is to suspend our mind, and shift our focus of awareness from being located in our mind, to turning the focus of awareness on and within awareness itself. The suspension of mind may be considered as a form of the phenomenological epoche, and the turning the focus of awareness within awareness itself is a form of the phenomenological reduction.

Through this simple praxis a person can establish their sense of self within the light of transitional awareness and begin to experience the qualities of the spacious field of direct knowingness of Being. And a person can integrate their mind into their transitional field of awareness. The transitional field of awareness is the field of Being in its manifestation as the openness of primordial awareness.

Our mind knows through thinking thoughts, through feeling feelings, through experiencing sensation, through having memory and imagination. The mind knows forms as beings and as things. Mind knows difference. The mind knows duality. Awareness knows Being. Awareness knows the sense of oneness and our innermost awareness is the sense of inner self as Being. Awareness knows non-duality. Awareness knows oneness. Awareness knows presence.

The language of transitional space is naturalistic and can be entered into through various ways. Sometimes the transitional state is described as an intermediate area of experience or in-be-tween. This space of Inbe-tween is in-between reality and fantasy, in-between thinking and feeling, in-between memory and sensation and in between thoughts and functions of the mind. This felt sense of this inner spaciousness opens and expands beyond our body boundaries. Sometimes the transitional space is also described as potential space. In this personal state or place there is a shift in located-ness from being located within the mind alone, and or even a singular functions of the mind such as thinking, or feeling, 
or sensation or memory into being located within the innermost field of awareness. To be located in awareness is to be located in the field of Being. The Openness of Being and knowingness of Being is Transitional Awareness. Our Being knows the Being-ness of beings.

This innermost field of awareness is the experiential self, and is the experiential field of Being. In this movement the innermost field of awareness becomes the experiential base of Being of our personhood. The true base is not the mind nor functions of the mind. The mind knows forms and beings and things. Awareness knows Being, and awareness knows the sense of embodied Being. The basic sense of self is no longer mind or even a function of the mind, but the innermost sense of Being and the Being-ness of Being. Winnicott describes the basic sense of self as the experience as the ongoing continuity of Being. There is a tension between mind as form and awareness as the field of Being. There is a tension between form of mind and the formlessness of Being.

\section{Embodiment of Being}

Transitional space can provide the "felt immediacy" of absorbed experiencing without reflective appraisal. Every person can at times manifest the existential concerns of borderline states of experiencing such as unbearable absence of the sense of Being and sense of embodiment. Within the experiencing of transitional space and transitional relatedness the person is more able to feel the embodiment of the field of Being as actual. Within transitional awareness, the person can be more focused, more absorbed in, and experience more substance to their bodily felt feelings of embodied Being. Embodied feelings are held within the embodied field of Being. The embodied sense of Being is 
Presence. In the union of mind and awareness we can experience the presence of phenomena and the phenomena of presence.

Our embodiment of the field of Being opens us to experience the field of Being of others and the field of Being of the world itself. The person not only experiences the field of Being within their own embodiment of mind and body, but also can experience the field of Being within others. In transitional awareness, a person is more able to be in resonance to the field of Being within others. And moreover, the person is able to experience the field of Being of world. One can begin to feel and live life in the sea of Being. Living within the sea of Being is naturally blissful and naturally self- liberating. Bliss is the pleasure of experiencing Being.

Living within transitional awareness provides freedom from one's preoccupation with one's mental presentation of self. Living within transitional awareness can provide freedom from the internalized demands to act "as if" to use Helene Deutsch's words and to perform a prescribed role. These prescribed roles may be a substitute for a truer sense of inner embodied self, inner embodied self-action, inner embodied self- manifestation, and the inner embodied sense of ongoing continuity of Being.

\section{As If Existence}

As Winnicott (1965) and Guntrip (1969) point out, the borderline experience of concern, is the experience of not having an autonomous sense of embodied Being as embodied self. As an empty person or beingless person we feel "as if" and the world feels "as if". There is a sense of unreality to our ongoing experience of self and others. One borrows roles and behaviors often of parental origin which are not one's own and play out that which they believe the Other wishes them to be. Without the 
embodiment of self, self- agency and self- direction do not come into Being, do not come into self- manifestation.

Consequently, there is the internal experience that one's behaviors and one's roles are "not me", but the behaviors and experience of action seems "as if". To use Winnicott's language the person substitutes a false sense of the disembodied self for the lack of the true sense of embodied self and the corresponding sense of self actuality, and most importantly a sense of self as ongoing continuity of Being.

\section{Being-less Identity}

The borderline experience requires that a person's publicly presented identity is not his inner identity--an identity which is felt to be hidden and uninformed and empty of Being, without Being. The borderline inner experience is of an inner sense of Being-less-ness and self-less-ness. The person feels the paradoxical experience of Being-less being. The experience of living within transitional space can, consequently provide a person with the novel experience of simply Being without constant pressure of empty performing and without the pressure to act out some fantasied image of what might be. The person begins to live slowly but surely within the Being-ness of their own Being. Our sense of our Beingness is our sense of self. Our sense of Being and our sense of Self are intertwined.

This liminal space of the transitional state opens and deepens our sense of embodied Being, embodied self, embodied resonant selfsoothing, and most importantly the awareness of one's own embodied awareness. To become aware of our own awareness is to become aware of the Being-ness of our own Being as self. 


\section{Wording of Innermost Experience}

A person can also speak and language their inner experience within this dimension of transitional space. This speaking from within the transitional experience facilitates the process of embodiment. Speaking experientially near, and within the felt sense of the experiential self deepens our embodiment of our self. This form of experiential speaking can facilitate the internalized experience of substance and embodied feelings. The internal experience of embodied awareness opens the possibility of our embodied sense of the Being-ness of one's own being encountering the Being-ness of others and the Being of the world.

The very ritual of becoming aware of awareness, entering into experiential transitional space and remaining in transitional awareness can provide a experiential structure for the person to tolerate, hold and metabolize subjective states of experience that are painful and fearful. Being in the Transitional space of awareness allows us to experience intense and painful states of experience without being totally organized and completely saturated by the painful state. The field of Being infuses and defuses the painful and saturating states of experience. The field of Being, as radiant awareness can infuse and metabolize saturated states of experience.

\section{Metabolizing of Experience}

This next statement is most important and most fundamental in understanding the power of the field of awareness. The awareness field of Being metabolizes and dissolves experience. The awareness field of Being metabolizes painful and fixated states of experience. The awareness field metabolizes saturating states of affect, saturated states of thought, saturated states of sensation and saturated states of physical pain. The 
awareness field of Being metabolizes dissociated fantasy and dissociated states of affect. In the metabolism, these states are integrated into the field of transitional awareness.

The awareness field metabolizes bliss, and metabolizes love, and metabolizes happiness, metabolizes erotic experience. The mind does not have the power to metabolize traumatic experience as does the field of awareness. The mind understands the context of experience and the mind understands the signification of experience. The mind understands the sensation of an experience and the mind understands the historical manifestation of experience, but the mind does not directly metabolize the experience. The mind does not directly digest the experience, transforming the experience into energy, vitality, light. The mind does not truly liberate the experience and does not liberate us. Our mind contextualizes experience and the meaning of experience.

The metabolizing process of the awareness field is much more powerful than our mind's capacity to metabolize experience or events of experience. To metabolize the experience of thoughts, sensations, memory, fantasy, and immediate experience is self- liberation. The stabilized state of awareness can metabolize traumatic experience and traumatic memory and somatic fixation. The true power of transitional space is the power of metabolizing. Inflammation is a function of metabolizing limitations.

By focusing on awareness of awareness, and remaining for a sustained time in this transitional state of awareness is a powerful instrument in the metabolizing of experience. Awareness of awareness is like the development of a powerful digestion. Awareness transforms "experience" into vital energy and luminous knowing. The field of transitional awareness transforms human experience into energy, light, embodied knowingness. 
Awareness is a field of knowingness, a field of energy, a field of spaciousness, a field of light and a field of the self- illumination of phenomena. This field of radiance light is the metabolizer of experience. The metabolizing of experience brings forth energy and vital-ness and illumination of embodiment. The metabolizing of experience brings forth the metabolizing energy and corresponding embodiment of the radiance of light. In the metabolizing of experience, energy and vitality and luminosity of awareness is increased. In the metabolizing of experience the deepening embodiment of luminous awareness takes place naturally.

A terrible existential fear of a person is to become stuck in the catastrophic and primitive experience of unbearable absence of Being and corresponding unbound desperate rage within the sense of there being no way out of infinite vacuum of emptiness. Consequently, the person is terrified of touching and entering the primitive painful feelings of annihilation and the internal abyss like states of absence.

Moreover we are able within our state of transitional awareness to integrate our states of mind, and states of affective experience into this open luminous transitional space of awareness which is the field of Being, as our own direct knowingness. In living within the field of transitional awareness, a person is more capable to hold and metabolize experience and maintain boundaries as to what will happen within themselves. To integrate experience into the field of awareness, is to liberate one's self within the field of human experience, within the field of Being just as we are.

The person begins to experience that the painful states of feelings can be directly touched, experienced, contained and assimilated and metabolized by the field of embodied Being of awareness. The person is more free to experience everything and anything within their range of lived experience. Painful feelings and affective experience can be 
metabolized and digested in a unfolding step by step movement of integrating everything and into and within the field of awareness which is the field of Being. A person does not have to use dissociation and detachment as the only way of freeing oneself from painful states of experience and painful states of memory.

\section{The Existential Base of the Field}

Without the sense of the base of field of awareness, intense affective states of fear and terror as well as forms of self-negating experience can become completely saturating and consuming. In saturated states of experience, intentional and even reflective capacity is often dissolved in the context of saturation. Terror and annihilation anxiety can saturate us and consume our intentionality and our minds reflective capacity. The intentional function of mind disappears in saturating states of overwhelming and intrusive painful experience of agony.

\section{Secret and Hidden Self}

As Guntrip (1969) and Eigen (1973) have pointed out, the core experience of both the schizoid experience and borderline experience is the emptiness of Being-ness or absence of embodied self, the inner conviction of being absolutely nothing and the sense of falling, falling falling into endless hollowness. Transitional states of awareness may be used in the context of the relationship with the psychotherapist as a vehicle for the patient to go into and inward, and possibly discover the hidden or split off secret self to use Winnicott's phrase. The secret self is the implicate sense of our inner most sense of vital Being-ness that has been lost in dissociating and fragmenting experience such as dissociative 
trauma, and as dissociative, fragmenting developmental states of splitting.

Winnicott speaks of a true, silent, inviolable sense of our innermost being as self, beyond all our usual communication with the outside world (Winnicott, 1965). Elkin (1972) and Guntrip (1969) also describe the schizoid retreat as a process in which an aspect of self- retreats to a hidden, detached existence to preserve a sense of psychic freedom and safety from impingement and abandonment.

This innermost sense of self is the inner most sense of Being-ness that is our inner sense of self. Our sense of self is our sense of Being and our sense of our Being is our sense of self. Our sense of self is intertwined with our sense of Being and our sense of Being is intertwined within our sense of self. In this description the borderline experience in essence is a schizoid state of absence of self, and absence of sense of inner most Being (Bauer, 2019).

\section{Ontic Ontological Beings We Are!}

We are ontic ontological Beings. Ontic refers to our mind and our body and ontological refers to our formless sense of Being. Our embodied mind and Being are intertwined. The borderline situation is an ontic ontological existential human problem.

Consequently, one's focus of psychotherapy is to facilitate ongoing contact- fullness with this hidden inner sense of Being as self. In this context, our hidden inner sense of Being has been dissociated from our mind and body. A person can withdraw deeply within beyond their inner sense of fear and terror of abandonment and annihilation (Eigen, 1973). As we pass through that field of emptiness we may discover the hidden self and concealed self- contained self. 
Once such contact with this innermost sense of Being as self has been established deeply within us, then person's viewpoint of himself as being intrinsically empty or hollow, may be reversed. The possibility of his entering into the world of embodied Being and embodied feelings is increased and the embodied life of Being in the world is increased. This is not a function of mental understanding but the direct immediate experience of the field Being deeply hidden within us. This sense of the field of Being is the sense of presence, pure presence.

This drama of transitional awareness is also the power of meditative awareness that focuses on our innermost awareness of Being. Dzogchen Meditation as well as phenomenological meditative practice has this focus of awareness becoming aware of awareness which is the opening of awareness to the field of Being that we are. Awareness of awareness meditation is not mindfulness. Being aware of our mind is not being aware of awareness. Being aware of our mind is not being aware of our Pure Being just as we are. Being aware of Being is called Rigpa in Dzogchen. Ma Rigpa is the experiential absence of our awareness of Being. Ma Rigpa means not knowing Being (Bauer, 2012).

\section{Pure Being Experience}

A wonderful description of the healing process of entering deep within inside and experiencing this, Pure Being experience, was written by Michael Eigen and published in The International Journal of Psychoanalysis (Eigen, 1973). Eigen describes this sphere of "am-ness" or pure presence as the innermost sense of personal Being-ness. Eigen describes how, over a number of months, a person withdrew from social contact and was increasingly experiencing fear of his sense of embodied Being-ness disintegrating. Disintegration is the experience of falling 
apart of our sense of embodied Being-ness, which is the fragmentation of our sense of innermost self. St. Augustine in the $6^{\text {th }}$ century $\mathrm{CE}$ also writes about this innermost sense of awareness as our innermost experience of luminous Being.

Eigen describes further how in psychotherapy this person actively allowed and tried to experience and self- manifest his experience of disintegration. The person tried to bring about the disintegration that he feared so terribly. When he surrendered to the experience of disintegration, he found it did not happen. What he feared did not happen. The person then felt the increasing courage to face whatever might come forth.

Whatever was to be experienced, he felt he could both experience and metabolize the experience within the spacious field of his innermost awareness. He felt his state of transitional awareness could hold and metabolize difficult sensations, and painful memories, and even the dreaded experience of non being or Being-less-ness. Paradoxically, his metabolizing of Being-less-ness, and metabolizing the absence of felt sense of Being actually brought forth the sense of Pure Being, Pure Presence of Pure Self. Metabolizing, within the field of awareness is like a great digestion that dissolves and absorbs experience and transforms experiences into vital energy and luminous knowingness (Beahrs, 1974).

\section{The Depression Beneath Depression}

As we embody this unfolding field of awareness, our primal fear of disintegration of our Being can be followed by an intense sense of emptiness of Being or absence of Being. This absence of Being some people described as a "the depression beneath depressions". This emptiness or this sense of unending absence is like a cloudy medium 
through which we feel a sense of "a hidden" awareness or hidden pure presence beyond and through this cloudy medium of emptiness or absence which draws us deeper into this medium of non Being. The emptiness can feel like a cloud, a vague cloud and we can sense through it, feel through it .Sometimes we can feel the inner presence within us on the other side of the cloud or beyond this dreary realm of emptiness.

\section{Meditative Gazing}

Meditative gazing within our own being can bring forth the presence that is innately within us as the very base of our Being. As we openly gaze within we can feel and sense the depth and breathe of this innermost Being of our own Being. It's me, but more than me. It is the "I am that I feel I've always been and that I've been moving endlessly toward, and yet this sphere has been pulling me to it from within and compellingly magnetizing me somehow. . like a compelling radiant source."

The person gazes within this "Aham" or "I am-ness" and is moved into the unborn and undying spaciousness of pure Being. As he entered this pure openness, the openness and the energy of the openness became more intense, more alive with itself, more vital and yet still, like the eye of a storm. Though soundless, this sphere gave the illusion of being loud. "It felt like this sphere is to giving birth" in self manifestation. When the loudness reached its peak, the space became clear instead of cloudy. "It then seemed immovable . . remaining in one place . . like a light tower or a bright, dense stone . . black space endlessly around it . . I wished to touch and enter completely into this sphere as though I would unite within it ....Ifelt as though I'm breakable and it's not . . I want to unite with it and make it part of me . . It is . . more me than me . . the I-ness of my I". ..” (Eigen, 1973). The person experienced this profound hunger to 
become one with the felt sense of self, the felt sense of ones embodied Being. The felt sense of inner self may be felt as a sphere of held and contained "Being-ness".

\section{Falling-Falling and Falling}

One of my own clients, a young man who has been experiencing the despair of his repetitious approaching towards and then rejecting the woman with whom he lived, and who he feared to get close to because he would either be absorbed by her or eventually abandoned by her. In and through his experience of the transitional space of awareness, he entered into his despairing feelings, giving up, so to speak, and then described the experience of falling-falling-falling into endless void-ness. He was falling, falling into the endless of emptiness of Being-less-ness!

As his experience shifted from being lost within the void-ness of emptiness, his sense of "I ness" briefly disappeared. He became briefly unconscious. Then awakening from the unconscious state, he began experiencing himself in a frozen state as if he was frozen and locked in ice. He began to experience cracks in the ice, and then a little further in time, he began to see light and experience energy coming from within his frozen compressed contained sphere of innermost self.

\section{Deadness}

There was this spontaneous shift within him in which he began to experience warmth and energy manifesting from deep within his heart center. He began to emerge becoming free of the compression and free of the frozenness and he began to feel highly energized and alive. He began to directly know that inside he was alive and not dead. The sense of deadness of self- disappeared (Eigen, 2004). 
His constant preoccupation with being not real, of being dead inside, and of being only a moving mechanical body left him, completely left him, and he began to experience inner laughter at the unwarrantedness and absurdity of his relentless self- doubt and his relentless self-critical examinations. He directly knew of his lively inner self, and directly experienced knowing his own inner experience of his innermost vital Being.

These liberating events ought not be considered as a cathartic breakthrough, but rather, the beginning of a reversal process. By going through the fear of despair, by going through the void-ness, by going through the emptiness and frozenness of Being-less-ness, the person made contact with an innermost sense of self as Pure luminous Being and began the process of reclaiming the energy and aliveness which had been so compressed, hidden and concealed.

The field of awareness of the field of Being is the field of open spaciousness, vital energy and self- illuminating light, illuminating our own Being and the Being of phenomena. The opening of the field of primordial awareness unlocks the phenomena of pain and phenomena of loss, and unlocks the felt sense of Being that infuses and permeates our experience of our personal Being as we well as experience of the Being of phenomena and the phenomena of Being.

After such an opening up experience, the world appears to the person to be luminous, multidimensional, compelling attractive, and appears to be home. Home is where the heart is. This liberating experience provides a profound shift in our perception of the world that gives support and hope for living within the sea of Being in this life and even beyond this life. Furthermore, this is not a once-and-for-all event, but may reoccur with different nuances, variations; hopefully ever deepening and nourishing. 


\section{Process of Going Inward}

Eigen (1973) describes the pattern of the process of going inward to reclaim this aspect of one's essential self as pure awareness and as the pure Being of awareness that was developmentally or traumatically cut off may be described as follows:

1) Disillusionment with the outer world and despairing over a meaningful life within the world.

2) Withdrawing inside, withdrawing deeper and further into innermost awareness.

3) Intense panic and fear of disintegration of one's sense of Being and as one's sense of self.

4) Intense feelings of emptiness of Being in which emptiness or void is eventually discovered to be the field of awareness which is to be alive and full. The emptiness becomes pure openness of pure Being. The inner sense of the Presence of Being replaces the absence of Being.

5) The experiencing of an underlying and indestructible sense of Pure Being as self-highly energized, although a condensed sense of self as awareness. This sense of awareness becomes embodied in the field of the body and expands into the world and comes into resonance with the field of Being of the world.

6) A reviewing of the world as being highly attractive and compelling and the beginnings of feelings of compassionate generosity within one's boundaries.

Although this process may and does take place spontaneously in ongoing relational life, the person within transitional awareness, compresses the experience, seems to by-pass defenses, and makes the inner journey more directly and more rapidly. 


\section{States of Mind and The Splitting of Mind}

The experience of Transitional Space of Awareness can be used to facilitate the integration of the split states of mind which have become disconnected ego states. A disabling experience of the Existential borderline life concerns being split into good states and bad states of mind. This splitting of affect takes place both in the sense of our self and our sense of otherness as object. We find our sense of self as good self and bad self and the other as good other and bad other.

There is splitting of affective states fragments our sense of self and fragments our sense of ongoing continuity of Being and fragments our sense of relationship with another person. Affective states with positive valence are maintained separate from affective states with negative valence both as to our sense of self and our sense of other. This relentless splitting makes the ongoing continuity of relationships with others impossible.

\section{Affective States of Form}

These affective states are affective states of form. This splitting is experienced because the negative affective states of mind being so intense, would seemingly destroy the positive affective states of mind. Often the split is experienced as being either all good, placating, dependent, and childlike, or, on the other side, being completely demonic, evil, destructive, rage filled, and totally non- relational (Masterson, 1976).

These psychological states are "affective" forms or forms of affect containing and influencing our states of Being. When these affective states are sustained and contained and maintained within the field of awareness, and the corresponding field of Being of awareness, then there can be the ongoing integration of these different affective states within 
the field of Being or within the field of the self. This field of Being supports continuous relationship between the different affective states of experience within us. These different affective states of mind are held and sustained within the field of awareness. This happens when mind and awareness are integrated. When the mind is integrated into the field of awareness, the mind is integrated into the self, integrated into the field of Being, and into the base of awareness. This integration completely supports a continuous ongoing experience of the stability of self and stability of the sense of ongoing continuity of Being-ness.

\section{The Non Dual Base of Transitional Awareness}

There is the non-dual base of our Transitional Awareness holding and containing these various and different states of affect. There is the base of Being of our being and these various intense affective states are integrated into the BASE OF BEING of Transitional Awareness. The various affective states are integrated into our sense of ongoing continuity of Being.

When these affective states and these affective forms are split off from the field of awareness, split off from the field of Being, split off from the field of the self, then there is no longer a base, a field of Being that holds and infuses the different forms of affect in relationship within the field of Being. This creates unbearable affective splitting with us and between us and others. The affects become thing like, the affects become concretized.

\section{Base of Being is the Medium of Integration}

Fragmented states of affect no longer have a base of being within Being. These affective forms of feeling are states of affect that are no longer affective states reflecting the support of the base, and infusion of 
the base of Being. Without the base of Being, the affective states of form cannot be integrated with each other, because the base of Being is the medium of integration. The base of transitional awareness is the medium of integration of the various affective states. Without the base of Being, the affective states are no longer part of the field of the self. They are dissociated parts or ego states or states of mind dissociated from the field of Being which is the field of the self and the field of awareness. The ego states become isolated and lack relatedness. They become self- contained entities. The ego states are dissociated and self- contained. Without the transitional space of awareness there is no medium for integrating the paradoxical affective states of experience such as love and hate, goodness and evilness, rightness and wrongness, truth and falsity.

\section{Lack of Foundational Being}

In this dissociative context the sense of the self is no longer the base of affective experience. The forms of affective states have been dissociated from the field of Being, the field of the self, the field of transitional awareness. These forms of affective states are mind alone experience. These affective states or ego states of mind are dissociated from the field of awareness, the field of self, and the field our Being. There is no base of Being. This is a fragmented experience of isolated, and isolating states of affect which become distinct states of mind and distinct ego states. These states are absent of the presence of foundational Being. This is most important to know. We wish to integrate our dissociated states of mind within our field of awareness, within our field of self, within our field of Being. 


\section{Coalescence of Good and Bad States}

Normal personal development involves the coalescence of good and bad states of self- experience, which although different from each other, are integrated and sustained within the sense of continuity of self, the sense of the continuity of Being. The sense of the non-duality of Being is within the self. The relational affective experience will not become fragmented and split because the affective states are not separated or dissociated from the base of the Being of the self of the person. This is the essential difference between integration and/or dissociation. The experience of non-duality or Oneness is not only a possibility between us and others, but most importantly even between and within our self. This last statement is most important in understanding the drama of oneness and separateness, oneness and fragmented-ness, Affective rupture and continuity of experience requires the field of non-dual Being which is the knowingness of field of Awareness.

For many people affective states are contained in mind alone without the base of awareness which is the base of Being, which is the base of the self. For many people their affective states are fragmented and fragmenting. For many people, there is no sense of ongoing continuity of Being or ongoing continuity of self. Their identity shifts from affective state to affective state. Without the base of Being, without the base of transitional awareness, without the base of inner self, the person has no stability of Being and no stability of awareness and no stability of self and so they fall into the abyss of nothingness. These shifting affective states become the false base of the self a base that lacks Being, a Being-less selfless base. This loss is a profound loss of humanness.

This is an important and necessary distinction. Understanding this distinction will provide information to bring forth the integration of dissociated affective states. These states must first be integrated within 
the field of Being, which is the base of Being or base of Self and the base of Transitional Awareness. Then these affective states can be integrated within each other within the field of Being which is the field of the self which the field of Awareness. Without the base of Being, integration will not be sustained. Without integration human beings suffer personally, relationally, and culturally. Of course as always, children bear the brute burden of this ignorance of Being.

\section{Necessity of Integrating Affective States of Mind into the Field of Awareness, the Field of Being}

There is the integration of these affective states within the field of self, within the field of Being, within the field of awareness. The integration of affective states of mind can take place within the field of awareness. There can be oneness within the self, and oneness within the field of Being of the different states of the various affective experience. If the affective states of experience cannot be integrated into the base of the self, which is the base of awareness and which is the base of Being; the integration of the diverse affective states will be most difficult if not impossible to integrate and be sustained with each other.

\section{Terror of Annihilation Anxiety}

When affective experience splits off or dissociates from the base of the self or the base of Being or the base of awareness, then the experience of emptiness and lack of Being arises and annihilation anxiety becomes pervasive. The experience of affective states of experience without the base of Being can be so painful. The experience of affective states without the base of Being can be painful, irritating, mechanical, and most of all thing like. Affective states without the base of Being or base of Self feel 
de-personal or non- personal. It is as if we are possessed by the affective state of experience.

\section{Negative Hostile Introjected Experience}

Kernberg points out that an important cause of failure in making this necessary coalescence is the predominance of the negative hostile introject, which is the disowned or "not me", affective state to use Sullivan's phrase (Kernberg, 1967). The not me or the negative hostile introject is a twisted state of mind that completely dissociates and splits off from the field of innermost awareness, from the field of self and from the field of Being. This affective state of experience becomes a "not me" and in fact a "thing like experience". These "not me" affective states become non personal or de- personalized fragments of personhood.

\section{Feelings Become States of Mind Isolated from the Field Of Being}

This sense of a non- personal feeling becomes a state of mind isolated from the innate field of Being. This affective form becomes an affective thing without Being. Affective integrated states are felt as feelings of different nuances of Being. Forms of affect may or may be not be split from the field of Being. When the form of affective experience is not split from the field of Being then these affective states exist within the field of Being and can be easily integrated and enter into dialogue with the other affective states within the field of Being. When the affective experience is split from the field of Being which is the field of the self, which is the field of awareness, then this affective experience becomes an ego state, a state of mind, a state of a thing, a non- personal state of mind within our mind. This is a maddening experience. 


\section{Forms of Affective States Should Not be Dissociated from the Field of Being}

When forms of affect are split from the Field of Being, when forms of affect are dissociated from the field of awareness, then these forms of affect become dissociative and depersonalized states without the connection within or to the field of Being, or to the field of awareness or the field of self. The not me, this negative introject is an intense dissociated non personal affective experience dissociated from our field of Being and our field of self and our field of awareness and becomes located in and contained in mind alone experience.

This distorting affective experience becomes a dissociated ego state or state mind.

\section{Ego States}

The field of Being is the integrative medium for affective states of experience. When the affective state of mind is integrated into the field of Being of the field of Transitional awareness, then the full integration of ego states or affective states of mind can be integrated into the sense of self which is the sense of Being-ness. The ego state dissolves and an affective feeling of a person remains.

\section{The Medium of Experience as the Field of Being}

The ego state is a state of affective experience of mind and without the field of Being as the base of the experience of the affect and as the medium of experience of the affect, a person cannot experience unifying the affective state of experience with other affective states of mind. The field 
of awareness holds and integrates the affective states of experience within the a continuum of experience, and within the continuum of personhood.

When affective dissociation takes place and is experientially distant from the innermost field of transitional awareness or self or field of Being, then the relentless splitting of affective states of experience takes place and each state is in isolation from the base of the field of Being which the field of self. Without the base of Being, the different affective states cannot be fully and relationally or personally attuned to each other. There is no medium of integration. There is no field of Being. There is no matrix of affective attunement of personhood.

\section{Dialogue With and Between States of Mind}

The experiential techniques of dialogue, in which the person gives a voice to his split affective states and then has the states enter into a dialogue with each other, can be heightened and deepened in transitional awareness (Bauer, 1976). The field of transitional awareness is the field of Being. The person must integrate split off affective states within the self and within the field of Being. When the split off states are re-grounded in the field of Being as the field of self, then these affective states can enter the dialogue of integration and attunement within the base of Being which is the base of personhood.

\section{The Splitting of Affective States of Experience}

There can be the dissociative splitting of the affective experience from the field of awareness. Dissociation of affective experience from the field of Being or field of awareness or field of self creates ego states or dissociative states of mind without the base of Being, or the base of self or the base of awareness. The affective experience becomes located only 
within mind alone. In mind alone affective states reflect a loss of personhood, loss of self- agency, and even a weakening of reflective intentionality. Dissociated affective states of experience are completely saturating and organizing of the personality. Dissociative affective states of experience are filled with pervasive force and dominating force.

The integration of the various affective experiences is very difficult if not impossible since there is no base of Being and no transitional continuum of Being that holds these various states of mind. These ego states become Being-less and become baseless and are without the unifying base of self or unifying sense of personhood. These baseless states of mind become painful and can induce further states of dissociation where a person can only dissociate and detach and enter a dissociative transcendental state of solipsistic existence for the sake of peacefulness. Peacefulness through absence!

The adolescent whose behavior shifts erratically from being "lovingly dependent and placating" to suddenly "rage filled, destructive and acting out", and who speaks of his mind wanting to kill his father and whose heart loves his father, can have these metaphorical representations of his split state enter into conversation within the context of the felt sense of the field of Being. But first each state must be integrated into the field of awareness which is the field of the self which is the field of Being.

Without this first step of integration then the dialogue will be endless and non- personal and only intensify the dissociative experience both in regards to the different and opposed states and more fundamentally, the dissociation will be increased between the states of mind and the field of Being. The ongoing continuity of Human Being-ness is a tentative experience. 
The young adult who seems frozen and all-placating and who intensely fears a vague demon-like creature within him -and yet feels clearly that it is not him- can give a voice to the demon and begin to reown and reintegrate the split of rage and placating ego states into the field of Being which is his field of self. This field of self is the field of Personhood. Both ego states are, in fact, are existentially fragmenting states of experience that influence our experience of our Being. Our sense of ongoing continuity of Being can be fragmented into all good states of self and or all evil states of self. When the experience of the affective state is felt within the field of Being then integration with the other different affective states of Being can be accomplished. Integrated Affective states are infused by vital energy and luminous light of Being and the luminous sense of oneness and sameness of Being. Una Voce as Duns Scotus would so often say.

The spoken gestalt dialogue in transitional awareness as the field of Being can facilitate re-owning of the split fragmented mind states within the field of Being of awareness. The person often consciously identifies with the placating good aspects of their Being and dis-identifies with the demonic aspect and consequently acts out dramatically the darkness. By consciously re-owning the evil part within the field of awareness, within the field of Being, balance and integration within field of Being are increased. The inherent power of transitional space is that the transitional field can hold intense states of paradox more easily for the person then when the person is located in mind alone.

The transitional space is the field of Being as our own awareness. The transitional space of awareness holds paradoxical experience within the context of non- duality or the oneness of the field of Being. This is an important understanding about the nature of the integration of opposites 
within the context the oneness of the field of Being. Without this understanding much integrative work ends in failure and despair.

Our mind naturally splits into oppositional parts of forms and when we are in the transitional field the dynamic pair of opposites are more easily held and synthesized into an integrated balance of our human range of experience.

\section{Metabolism}

Being in transitional awareness can be most helpful in the metabolizing of the phenomenologically felt to-be-evil bad introjected experience. The early introjected and unassimilated object of negation may be felt to be overwhelming, and may often be pre-conceptual which may only manifest as a vague sense or vague feeling of dread without imagery and without language representation. The person who is located in their in mind alone may be both unable and terrified to give to expression to this state of dreadful experience. The psychotherapist can help facilitate a person experiencing this introjected state of negation of Being by having the person experience the introjected state of negation within their field of transitional awareness which is the field of Being.

\section{Metabolism followed by Mentalization}

This integration of the introjected state of a affective state of mind into our transitional awareness field allows the introjected state of being to becomes manageable and containable and metabolized. Metabolization is the source of self- liberation. As the person integrates this introjected internalized state of being within their field of transitional awareness, this integration enhances the possibility of assimilation and metabolizing of this foreign state of being and its relentless intrusive affects. 
When this singular state of the mind is metabolized by and within the transitional awareness field, the process of metabolism can also take place. Mentalization is the process of formulating unformulated experience. Mentalization is a experiential skill based process for the clear formulation of experience. This skillful means process was developed Peter Fonagy (Bateman, 2006).

Mentalization allows experiential feelings to become transformed, articulated cognitively formulated as a clear representational experience in representational language. Mentalization follows metabolization. In time this representation of experience becomes a cognitive formulation of a past articulated experience, that is no longer compellingly affective and a relentless uninformed organizer of personal experience. The experience of transitional awareness illuminates our mind and our mind becomes a more effective instrument of mentalization. Mentalization is the skillful process of formulation of unformulated experience. Mentalization gives clarity of mind and clarity of thought reflecting a clarity of unformulated experience becoming coherently formulated.

For example, Myra, a young 25-year-old female plagued with vague, ominous rage, was often frozen and speechless in regard to her destructive and self-destructive feelings. In transitional awareness she was able to give form to these feelings as an image of an evil woman bent on killing her. After numerous experiential descriptions of her compelling experience within the field of transitional awareness, she began to experience her compelling dreadful state dissolving and disappearing.

\section{Self -Empowered Embodiment}

She began to experience the disowned energy and the aggression as her own, as her own self- empowerment. As her mentalization process 
continued to unfold overtime, there was the progressive growth from the pain of the internalized other, to the sense of self embodied empowerment. Through this self- embodied empowerment, Myra could take protective care of herself. Myra, began to re-experience her experience of the hostile introjected experience as her own newly found inner strength. After she assimilated and metabolized the introjected drama within the spaciousness of her transitional field of awareness, she became more efficient in her aggression and realized the adaptive aspects of her aggression and the power within her. She was able to assimilate and metabolize the rage and then mentalize her capacity to have healthy aggression and take protective action in a direct manner. She became empowered through her inner experience of embodied awareness and mentalized mind. Transitional awareness metabolizes experience and a supports the mind's capacity for effective and successful mentalization of confused and confusing experience.

\section{Conclusion}

I have described the use of transitional space as a method in working with the existential concerns of person. Transitional space provides a way for the person to become absorbed in their experiential world in an intense but contained way. This liminal state provides a ritual for the person to give focus and defined expression to his or her chaotic and undefined and unformulated experience. Although obvious, the use of transitional space described in this paper are strategies that might be used in the ongoing therapist-person relationship. The therapy relationship takes place within the mutually held field of transitional awareness. Of course this understanding belongs to human relationship and not only psychotherapy! 
It is important to understand that this transitional drama of becoming aware of awareness is a powerful form of meditative experience. This drama of becoming aware of awareness brings us into transitional space of awareness wherein lies our direct experience of the Being, of our own Being and simultaneously we can experience the Being of others. By becoming aware of our own awareness the field of Being is embodied. We can begin to think and feel and move within the field of Being. We can live within the field of Being and we can die within the field of Being. In living within this sea of Being we begin to experience the multidimensionality of this sea of Being that we are. We experience the ordinary life world of Being and as the manifestation of the life world as Being. We experience the archetypal dimension of the field of Being that is manifesting us as Beings. We can experience within our own being and the being of others and the being of the world the archetypal and elemental energies of vortices of light and energies that manifest as the archetypal energies. And then we can experience the foundational source of these dimensions of Being, which is pure Being as source. Through this phenomenological meditation we can experience these different dimensions of our own Being and this is self- liberation. Everyone experiences these dimensions in their own personal way. 


\section{References}

Bateman, A., \& Fonagy, P. (2006). Mentalization-based Treatment for Borderline Personality Disorder: A Practical Guide. Oxford, UK: Oxford University Press. Print ISBN-13: 9780198570905

Bauer, R. (1976). A Gestalt approach to internal objects. Psychotherapy: Theory, Research \& Practice, 13(3), 232-235. https://doi.org/10.1037/h0088346

Bauer, R. (2012). Meditation as Becoming Aware of the Field of Awareness. Journal of The Awareness Field, Vol 2, Awareness As Existing-ness.

Bauer, R. (2019). The Absence of Self: An Existential Phenomenological View of The Anatman Experience. Journal of Philosophical Investigations, 13(28), 171-179. doi: 10.22034/jpiut.2019.35653.2391

Beahrs, J. O., \& Humiston, K. E. (1974). Dynamics of experiential therapy. American Journal of Clinical Hypnosis, 17(1), 1-14.

Eigen, M. (1973). Abstinence and the schizoid ego. International Journal of PsychoAnalysis, 54, 493-498.

Eigen, M. (2004). Psychic Deadness .London: Karnac books, ISBN 13: 9781855753860

Elkin, H. (1972). On selfhood and the development of ego structures in infancy. Psychoanalytic Review, 59(3), 389-416.

Erickson, M. H., \& Rossi, E. L. (1975). Varieties of double bind. American Journal of Clinical Hypnosis, 17(3), 143-157.

Guntrip, H. J. S. (1969). Schizoid Phenomena, Object-Relations and the Self. New York (International Universities Press).

Heidegger, M. (1966) Discourse on Thinking, New York: Harper Perennial.

Kernberg, O. (1967). Borderline personality organization. Journal of the American psychoanalytic Association, 15(3), 641-685.

Mahler, M. S. (1971). A study of the separation-individuation process: And its possible application to borderline phenomena in the psychoanalytic situation. The psychoanalytic study of the child, 26(1), 403-424. 
Masterson, J. (1976). Psychotherapy of the Borderline Adult, Brunner/Mazel.

Winnicott, D. W. (1965). Communicating and not communicating leading to a study of certain opposites In The Maturational Processes and the Facilitating Environment New York: Int. Studies in the Theory of Emotional Development New York: International Universities Press, Inc, 179-192. 